\title{
MENTAL HEALTH IN RELATION TO EMOTIONAL INTELLIGENCE AND SELF EFFICACY AMONG WORKING PROFESSIONALS IN URBAN INDIA
}

\author{
archana jhangiani ${ }^{1}$ \\ ${ }^{1}$ Affiliation not available
}

July 20, 2020

\begin{abstract}
The objective of this research is to scientifically investigate the statistical significance of the relationship between Emotional intelligence and Self-Efficacy, as well as, of the multiple correlation of Mental Health with the linear combination of Emotional Intelligence and SelfEfficacy, among working professionals in Urban India. The population of interest is Urban Indian working professionals, 30-49 age group. A representative sample $(\mathrm{n}=50)$ was drawn from the defined population of interest through Purposive Sampling technique, of whom 50\% $(\mathrm{n}=25)$ were male and $50 \%(\mathrm{n}=25)$ were female participants. MHI-18, SSEIT and GSE were the three tools used and data analysis of the variables involved the use of Pearson's Product-Moment method of Correlation. Also F-distribution was used to test the statistical significance of the calculated percentage of variance in Mental Health explained by the linear combination of Emotional Intelligence and Self-Efficacy. The key findings suggest that SelfEfficacy and Emotional Intelligence are significantly positively and fairly strongly related. (rGSE.EI $=0.59 ;<0.01)$ and $35 \%$ of the variance is shared by the two variables. Regression analysis performed on the total SSEIT ( $\mathrm{x}$ ) and GSE (y) scores, revealed the $\mathrm{y}$ on $\mathrm{x}$ equation as ' $\mathrm{y}=0.14 \mathrm{x}+13.85$ '. Results also showed that Self-Efficacy, as well as Emotional Intelligence are significantly positively and fairly strongly related with Mental Health (rMHI.GSE $=0.68 ;<0.01$ ), (rMHI.SSEIT $=0.6$; $<0.01$ ). Finally, the findings also revealed a significant positive Multiple Correlation between Mental Health and the linear combination of Emotional Intelligence and Self-Efficacy (RMHI.SSEIT, GSE $=0.72 ;<0.01$ ). The calculated percentage of variance in Mental Health explained by the linear combination Emotional Intelligence and Self-Efficacy is 53 percent, which was found to be statistically significant. Hence the results support the position that Self-Efficacy and Emotional Intelligence are significantly associated with positive Mental Health of Urban Indian Working Professionals.
\end{abstract}

\section{Hosted file}

Final-MENTAL HEALTH IN RELATION TO EMOTIONAL INTELLIGENCE AND SELF EFFICACY.pdf available at https://authorea.com/users/344372/articles/470937-mental-health-in-relation-toemotional-intelligence-and-self-efficacy-among-working-professionals-in-urban-india 